\title{
COMUNICACÕES
}

\section{Cercospora apii em mastruz no Pará: primeiro relato}

Rosemary Corrêa da $\operatorname{Costa}^{1}$; Jaqueline Rosemeire Verzignassi²; Luiz Sebastião Poltronieri ${ }^{1}$; Ruth Linda Benchimol ${ }^{1}$; Eudes de Arruda Carvalho ${ }^{1}$

${ }^{1}$ Embrapa Amazônia Oriental, Tv. Enéas Pinheiro, S/N, CEP 66095-100, Belém, PA. ${ }^{2}$ Embrapa Gado de Corte, Avenida Rádio Maia, 830, CEP 79106-550, Campo Grande, MS.

Autor para correspondência: Jaqueline Rosemeire Verzignassi (jaqueline.verzignassi@embrapa.br)

Data de chegada: 02/07/2012. Aceito para publicação em: 12/10/2012.

O mastruz (Chenopodium ambrosioides L.) é uma planta herbácea de forte aroma, nativa da América tropical e originária do México. No Brasil, essa espécie tem ampla distribuição, com ocorrência em quase todo o território, onde recebe vários nomes populares: mastruço, mastruz, erva-de-santa-maria, chá-do-méxico, erva-formigueira e quenopódio. Sua ampla utilização deve-se à presença de elevados teores de ascaridol nas sementes, nas folhas e no caule (seu óleo essencial possui $90 \%$ de ascaridol). Os principais usos são: tratamento de ascaridíase; controle de artrópodes e pragas domésticas; inibição do desenvolvimento de fungos do solo e de insetos, como Scrobipalpula

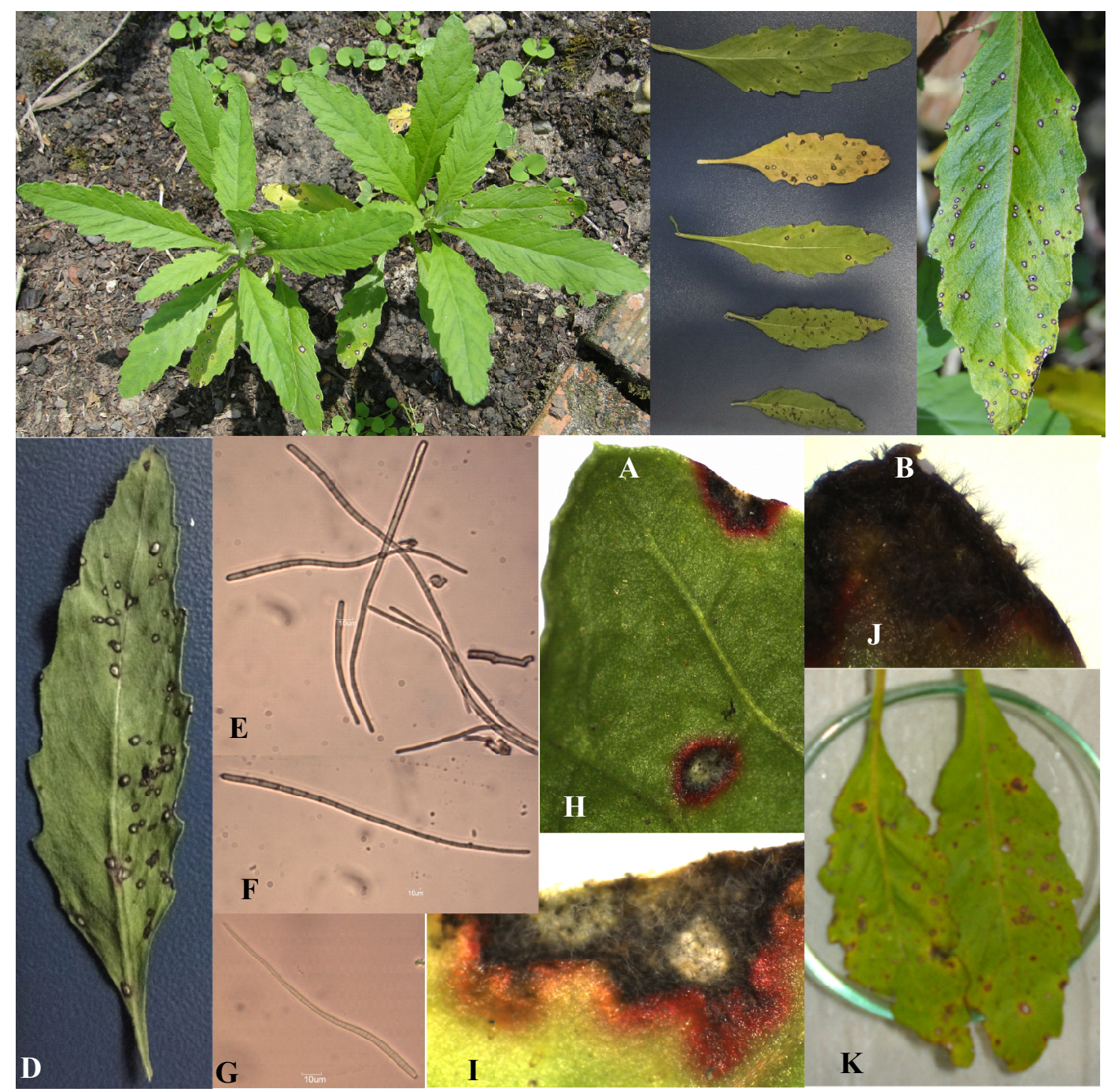

Figura 1. Manchas de cercospora em folhas de mastruz causadas por Cercospora apii: sintomas na face adaxial (A-C); sintomas na face abaxial (D); conídios do fungo (E-G); sintomas e sinais (H-J); feixes de conidióforos (J); sintomas em folhas destacadas inoculadas (J). 
absoluta (traça-do-tomateiro) e Spodoptera frugiperda (lagarta-docartucho-do-milho). No ano de 2008, em canteiros de plantas medicinais da Embrapa Amazônia Oriental, em Belém, foram observadas lesões foliares em plantas de mastruz jovens e adultas. As lesões foram caracterizadas, inicialmente, por pequenas manchas circulares, com centro pardo e halo amarelado, em ambas as faces das folhas (Figuras 1A a 1D). Na ocasião, plantas com sintomas foram enviadas ao Laboratório de Fitopatologia da Embrapa Amazônia Oriental para a diagnose do agente causal da doença. O isolamento foi efetuado a partir de pequenos pedaços de tecido do limbo lesionado, na zona de interface entre o tecido doente e o tecido sadio. Estes foram desinfestados em hipoclorito de sódio ( $2 \%$, por dois minutos), lavados em água destilada esterilizada e transferidos para placas de Petri contendo meio de cultura de ágar-água. As placas foram incubadas por sete dias a $26^{\circ} \mathrm{C}$, sob luz fluorescente e fotoperíodo de 12 horas. A partir de então, verificou-se a presença de colônias fúngicas e procedeu-se a multiplicação dos isolados obtidos em placas contendo meio de cultura BDA (Batata-Dextrose-Ágar), sob as mesmas condições anteriormente citadas. Após cinco dias de incubação, os isolados fúngicos foram levados ao microscópio óptico e foram observados conídios hialinos, multicelulares, septados, filiformes (Figuras 1E a 1G). Ainda, folhas com sintomas foram submetidas à câmara úmida $\left(90 \% \mathrm{UR} ; 30^{\circ} \mathrm{C}\right)$ por três dias e conidióforos negros, reunidos em fascículos densos (feixes de três ou mais conidióforos), foram observados (Figuras $1 \mathrm{H}$ a $1 \mathrm{~J}$ ). $\mathrm{O}$ fungo foi identificado como Cercospora apii. Folhas sadias foram destacadas de plantas de mastruz, submetidas a ferimento e inoculadas com discos de cultura (micélio do fungo + meio de cultura) em suas faces abaxial a adaxial. Ainda, discos BDA sem a presença do patógeno foram dispostos sobre as folhas previamente feridas, como testemunha. As folhas foram submetidas à câmara úmida por 48h, sendo mantidas em bandejas cobertas com sacos plásticos, em condições de laboratório. Após quatro dias da inoculação do patógeno, as folhas começaram a apresentar os sintomas iniciais demonstrados no campo (Figura $1 \mathrm{~K}$ ). O reisolamento do patógeno a partir do tecido lesionado resultante da inoculação confirmou ser Cercospora apii o agente causal das lesões nas folhas de mastruz. Ressalta-se que a planta foi identificada como Chenopodium ambrosioides L. no Laboratório de Botânica da Embrapa Amazônia Oriental e folhas com sintomas, utilizadas para as análises, foram herborizadas e armazenadas no Herbário da Embrapa Amazônia Oriental sob o número de registro 188064. Este é o primeiro relato deste fungo atacando plantas de mastruz no Estado do Pará. O agente causal da cercosporiose em mastruz, Cercospora apii Frensen., apresenta as sinonímias Cercosporina apii (Fresen.) Miura (CABI BIOSCIENCE; CBS; LANDCARE RESEARCH-NZ. Index Fungorum. 2012. Disponível em http://www.indexfungorum.org. Acesso em: 03 set 2012) é um saprófita facultativo, passando a maior parte de seu ciclo parasitando seu hospedeiro (KOIKE et al. First report of a leaf spot disease of bells-of-Ireland (Molucella laevis) caused by Cercospora apii in California. Plant Disease, v.87, p.203, 2003). No Brasil, a doença foi registrada em mamoeiro (Carica papaya L.) no Ceará; em Agastache rugosa (Fischer \& C. Meyer) Kuntze, Amaranthus sp. L., Angelonia sp. Humb. \& Bonpl., Anthurium sp. Schott, Apium graveolens Cham., Castilla elastica Sessé in Cerv., Chenopodium ambrosioides L., Citrullus vulgaris Schrad. ex Eckl. \& Zeyh., Cucumis melo L., Hydrocotyle sp. L., Malpighia emarginata DC, Malpighia sp. Plum. ex L., Petroselinum hortense Hoff, Physalis sp. L., Pueraria hirsuta Kurz, Raphanus sativus L., Senna alata Roxb, Senna occidentalis L., Spigelia anthelmia L., Tagetes sp. L, Terminalia catappa L., Verbena sp. L. e Vigna unguiculata (L.) Walp. no Rio Grande do Sul, São Paulo, Minas Gerais e Sergipe; em Apium graveolens L. var. dulce (Mill.), Apium rapaceum Mill., Carica papaya L.; no Distrito Federal, há relatos em plantas de Vitex agnuscastus Kurz, Wedelia paludosa DC. e Zinnia elegans Jacq. (MENDES \& URBEN. Fungos relatados em plantas no Brasil, Laboratório de Quarentena Vegetal. Brasília, DF: Embrapa Recursos Genéticos e Biotecnologia. Disponível em: http://pragawall.cenargen.embrapa.br/ aiqweb/michtml/micbanco01a.asp. Acesso em: 03 ago. 2012). 